\title{
O direito à terra indígena no Brasil: de garantias constitucionais a conflitos privados
}

\author{
The indigenous land right in Brazil: from constitutional guarantees to private conflicts
}

Iasmim Madeiro Cordeiro*

Adriano Marteleto Godinho**

\begin{abstract}
REFERÊNCIA
CORDEIRO, Iasmim Madeiro; GODINHO, Adriano Marteleto. O direito à terra indígena no Brasil: de garantias constitucionais a conflitos privados. Revista da Faculdade de Direito da UFRGS, Porto Alegre, n. 44, p. 20-49, dez. 2020. DOI: https://doi.org/10.22456/0104-6594.94998.
\end{abstract}

\begin{abstract}
RESUMO
O direito à terra indígena no Brasil é assunto discutido desde os primórdios da colonização. Os conflitos existentes acerca da propriedade, posse e usufruto das terras indígenas ultrapassam o meio público e resultam em conflitos envolvendo direitos dos não indígenas que, por vezes, possuem títulos de propriedade privada devidamente registrados em cartório, consoante as normas do Direito Civil brasileiro. O trabalho ora escrito visa evidenciar que o direito dos povos indígenas deve ser adequadamente efetivado, conforme garante a Constituição Federal de 1988, com auxílio do Estado. A metodologia adotada seguiu a pesquisa bibliográfica e jurisprudencial. O método pelo qual a pesquisa pautou-se foi o indutivo. A necessidade de ação estatal é verificada quando particulares não têm conhecimento do território destinado aos povos indígenas e conseguem registrá-lo como seu de acordo com as normas do Código Civil, momento em que a demarcação das terras indígenas, ato meramente declaratório, alcança um valor inestimável, podendo resultar na diminuição de conflitos e consequentes processos judiciais. Concluiu-se que diversos são os enfrentamentos acerca do tema em epígrafe, restando evidente que o direito dos povos nativos brasileiros, minoria vulnerável, deve ser resguardado, tendo em vista ser essencial para a manutenção de seus valores, crenças, identidade e costumes.
\end{abstract}

\section{PALAVRAS-CHAVE}

Povos indígenas; Constituição; Conflitos de terras.

\section{ABSTRACT}

The right to indigenous land in Brazil has been discussed since the earliest days of colonization. Existing conflicts over the ownership, possession and usufruct of indigenous lands surpass the public environment and result in conflicts involving the rights of non-Indians who, sometimes, have private property titles duly registered in a notary's office according to the norms of Brazilian Civil Law. This article intends to show that the right of indigenous peoples must be duly enforced, as guaranteed by the Federal Constitution of 1988, with the assistance of the State. The adopted methodology was the bibliographical and jurisprudential research, which was based on the inductive method. The need for state action is verified when individuals are unaware of the territory destined to indigenous peoples and can register it as their own, according to the norms of the Civil Code, at which point the demarcation of indigenous lands, a merely declaratory act, is of inestimable value, which may result in conflict reduction and consequent legal proceedings. It was concluded that there are several clashes about the aforementioned topic and it remains evident that the right of native Brazilian people, a vulnerable minority, should be safeguarded, as it is essential for the maintenance of their values, beliefs, identity and customs.

\footnotetext{
* Mestranda em Direitos Humanos do Programa de Pós-Graduação em Ciências Jurídicas da Universidade Federal da Paraíba (PPGCJ/UFPB), com bolsa de financiamento cedida pela Coordenação de Aperfeiçoamento de Pessoal de Nível Superior (CAPES), sob orientação do Professor Dr. Luciano Mariz Maia. Pós-Graduada lato sensu em Direito Civil e Processo Civil pelo Centro Universitário de João Pessoa (UNIPE). Graduada em Direito pelo Centro Universitário de João Pessoa (UNIPE). E-mail: <iasmimmc@gmail.com>.

** Professor na Universidade Federal da Paraíba (UFPB). Mestre em Direito Civil pela Universidade Federal de Minas Gerais (UFMG). Doutor em Ciências Jurídicas pela Universidade de Lisboa.
} 
KEYWORDS

Indian people; Constitution; Land conflicts.

SUMÁRIO

1. Introdução. 2. A questão indígena no Brasil. 3. O direito à terra. 4. O conflito relativo aos direitos originário indígenas e o direito à propriedade privada dos não indígenas. 5. Conclusão. Referências. Dados da publicação.

\section{INTRODUÇÃO}

O direito à terra sempre foi um assunto de grande relevância para qualquer indivíduo e, quando se trata de direitos indígenas, a análise do processo histórico de lutas e reivindicações por terras abarca um sentido muito mais profundo e espiritual, tendo em vista a relação que o mencionado povo detém com seu território, o qual faz parte do seu ser e de seus costumes, tradições, crenças e cultura.

O povo indígena, desde os primórdios do descobrimento do Brasil, foi vítima de grande violência, frente a uma sociedade colonizadora que sempre buscou integrar os indígenas como se fossem passivos de evolução social, econômica e cultura, por serem vistos como inferiores quando comparados aos demais indivíduos; nesse contexto, a resistência dos povos indígenas mostrou seu interesse e objetivo em defender e manter os seus valores e princípios, muitas vezes negados por uma sociedade supostamente civilizatória.

Destaca-se a importância em analisar a evolução do direito à terra dos povos indígenas, tendo em vista que diversos conflitos são verificados quando seu direito originário é confrontado com o direito dos não indígenas que possuem títulos de propriedade privada regidos pelo Código Civil Brasileiro, muitas vezes anteriores à própria $\mathrm{CF} / 88$.

Assim, o presente trabalho busca analisar a evolução do direito dos povos indígenas à terra, no âmbito da $\mathrm{CF} / 88$, em detrimento daqueles direitos consagrados pela legislação civil aos não indígenas acerca de títulos de propriedade, posse e usufruto, verificando como o ordenamento jurídico brasileiro reagiu a tais questões, uma vez que a luta por terras indígenas e a violação de seus direitos são problemas corriqueiros.

A garantia dos direitos indígenas no cenário da sociedade atual deve ser tratada como o preceito fundamental que é, tendo em vista que se está a referir a um povo que carrega em si a história e as raízes do nosso País. 


\section{A QUESTÃO INDÍGENA NO BRASIL}

Os povos indígenas, presentes no território brasileiro mesmo antes dos primórdios do descobrimento do Brasil, quando os portugueses aqui chegaram no final do século XV, passaram por diferentes problemas sociais decorrentes da colonização. A exploração da mão-deobra, escravidão, violência e toda a brutalidade imposta pelos colonizadores aos povos indígenas exprimem a árdua realidade pela qual esse povo passou na busca de sobrevivência.

Frente a uma sociedade colonizadora, a luta para manutenção da cultura e da dignidade dos povos indígenas foi intensa, ao passo que eles eram tidos como seres inferiores, desprovidos de valores essenciais para alcançar o desenvolvimento, sofrendo para manter suas crenças e costumes ou cedendo aos preceitos sociais já determinados.

Na busca de uma comunhão nacional, supostamente socializante, eram submetidos a uma política assimilacionista que almejava introduzir na comunidade indígena hábitos, valores e crenças provenientes de uma identidade dita civilizatória. Surgiria a necessidade de ultrapassar a barreira mental já habituada aos preceitos de dominação, aperfeiçoar a legislação para conceder tratamento digno aos povos indígenas, além de afirmar tais direitos em um universo internacional (CAVALCANTI, 2016, p. 4).

A resistência dos povos indígenas afirmou o empenho para a preservação de suas características coletivas e a sua identidade cultural. Desde os primeiros instrumentos legais que introduziram direitos indígenas na legislação brasileira, o direito à terra é colocado como um direito primordial, que abrange outros diversos direitos e características dos povos indígenas, que se tornam resguardados e efetivamente protegidos com a $\mathrm{CF} / 88$, que representa marco fundamental na garantia dos direitos de tais povos (JOAQUIM, 2013, p. 13).

Não obstante, a luta do povo indígena para adquirir espaço e manter sua dignidade e cultura permanece intensa. Os meios que asseguram a manutenção dessas condições constituem objetivos constantes, para que haja a possibilidade de permanência em suas organizações sociais, a liberdade para manter sua etnia e cultivar sua cultura, que evolui constantemente, mas que se mantém presente no seio dos povos tidos como minoria no cenário nacional e internacional. Para além disso, importa destacar as notórias e frequentes ameaças sofridas pelos povos indígenas, quando o posicionamento do poder executivo demonstra o interesse em retornar a uma política aparentemente assimilacionista.

Quando nos remetemos à cultura, verificamos que todos os que integram a sociedade possuem costumes e valores próprios do meio no qual estão inseridos. A diversidade cultural 
é enorme em todo o território brasileiro, sendo aceita, portanto, a autoidentificação étnica, juntamente com a autodeterminação, conceito presente no direito internacional, bem como no direito interno, para dar legitimidade aos povos que podem determinar suas próprias crenças, culturas e governo.

A manutenção de costumes e modos padronizados de conduta de determinados grupos faz com que seja possível a especificação de comunidades, ao passo que é dado a cada uma a identidade cultural (SANTAELLA, 2010, p. 44). A identidade cultural de um povo é percebida em suas transformações. A possibilidade de acrescentar características e atualizar preceitos culturais nos remete a uma mudança social sadia, que passa a ser entendida como uma forma de reprodução social analisada pela história.

Destarte, quando tratamos dos povos indígenas, é importante ressaltar que o seu direito à cultura merece um destaque especial, tendo em vista o reconhecimento da situação de vulnerabilidade presente após séculos de discriminação, além de políticas de extermínio de tal povo, bem como por toda dificuldade em conseguir definir e mensurar o que pode ser entendido por cultura em um universo em constante desenvolvimento (LOPES, UCHOA, 2018, p. 16).

Com o intuito de proteger e promover os direitos dos povos indígenas no cenário nacional surge em 1967, instituída pela Lei no 5.371, a Fundação Nacional do Índio (FUNAI), órgão indigenista oficial do Estado brasileiro. O movimento central das movimentações políticas sobre os povos indígenas se concentrava, a princípio, na busca pela garantia do direito à terra, que pode ser vista como a base para seu desenvolvimento, com grande diversidade sociocultural em diferentes grupos étnicos.

A luta de todo o movimento indígena, em especial no território brasileiro, vai além de reinvindicações de terra no sentido literal da palavra. Ao contrário disso, abrange a possiblidade de manutenção de sua cultura, a defesa do estilo de vida de cada povo, respeitando as suas particularidades. Fazer parte de uma parcela da população mundial reconhecida como minoria torna-se motivação para o enfrentamento de todas as formas de discriminação e rejeição, com o fito de efetivar direitos e gozar das garantias, hoje estabelecidas por diversos mecanismos legais.

A história dos povos indígenas é marcada por desigualdades de condições, crueldade, violência e discriminação, mediante a constante violação de suas vidas, sociedades e dos direitos às terras ocupadas e originalmente indígenas.

Souza Filho (2010, p. 76) menciona que o Estado nacional era dotado de direitos individualistas e que direitos coletivos, como o direito à terra dos povos indígenas, eram negados. 
Os povos indígenas eram vítimas de constantes ameaças, vivendo longe da civilização para preservar seus modos e costumes.

A terra para os povos indígenas sempre teve valor especial e essencial para a manutenção de seus preceitos culturais. Desde os primórdios, as primeiras determinações legais relativas aos povos indígenas tratavam de garantias sobre o seu direito à terra, como sendo um pressuposto indispensável para a condição indígena.

Contando com uma evolução lenta desde o período colonial, o direito dos povos indígenas passa por aprimoramentos, ao mesmo tempo em que é alvo de constantes violações, como também políticas integracionistas afirmadas durante anos na busca de uniformidade de culturas e ideologias, propagando valores universais (JOAQUIM, 2013, p. 23).

Não obstante, a defesa e garantia dos preceitos culturais e sociais dos povos indígenas constitui valor essencial para a sua comunidade; eles se consideram filhos da terra, onde seus costumes, crenças, valores e preceitos são consequência de um direito maior, hoje entendido como direito fundamental, qual seja, o seu direito à terra, que é produto de uma ligação profunda, íntima e de respeito com o ambiente.

Após anos de evolução, com o intuito de efetivar as garantias direcionadas aos povos indígenas, suas terras são legalmente destinadas à posse permanente e uso exclusivo das comunidades que as ocupam. O direito de ocupação das terras indígenas configura-se como um direito originário, como já mencionado, sendo os povos indígenas os seus ocupantes tradicionais e tendo como consequência a demarcação de suas terras, que possui natureza meramente declaratória.

Assim, a terra é reconhecida como indígena a partir de requisitos legais e técnicos, conforme determina a CF/88. Tratando-se de uma porção do território nacional, sendo propriedade da União, as terras indígenas são caracterizadas por serem inalienáveis, indisponíveis e os direitos sobre ela impostos imprescritíveis (FUNAI, 2019, p. 1).

Embora já existam diversos dispositivos legais referentes à proteção e à garantia dos direitos indígenas, em especial o direito à terra, é frequente a constatação de violações por invasores com interesses na exploração ambiental do espaço determinado às comunidades indígenas. Souza Filho (2018, p. 156) afirma que por diversas vezes os direitos de tais minorias são violados e a legislação não aplicada, sendo tais direitos considerados inexistentes, tanto pelo poder público que deveria resguarda-los quanto por particulares que ignoram a presença tradicional dos povos. 
Tais circunstâncias resultam no afastamento dos povos indígenas das terras originalmente ocupadas, e consequente minoração do seu povo, além da degradação do meio ambiente no seu território, o que interfere negativamente na sobrevivência e qualidade de vida dos povos que têm a terra como meio de vida e subsistência (IBGE, 2002, p. 1).

Ao analisar a evolução dos direitos indígenas, temos que o primeiro mecanismo legal que abordou direitos dos povos originários foi a Carta Régia de 10 de setembro de 1611, promulgada pelo Rei Felipe III ainda no Brasil Colônia. A norma trazia disposições sobre o direito à terra e o direito de locomoção dos povos indígenas; entretanto, ao mesmo tempo, tratavaos como povo não civilizado, que não tinha acesso à educação e não entendia as determinações presentes na lei, o que a tornava não efetiva.

No fim século XVII, em $1^{\circ}$ de abril de 1680 , o alvará régio estendeu o direito do mencionado povo. A partir de tal norma, os povos indígenas poderiam utilizar as terras que estavam outorgadas aos particulares, bem como manteriam o direito de poder permanecer em seus territórios, caso assim o desejassem (ALBUQUERQUE, 2017, p. 14).

A posse dos povos indígenas sobre as terras povoadas é reconhecida por Portugal por serem eles os primeiros ocupantes e donos naturais (ARAÚJO, 2006, p. 24). Tais direitos de liberdade e posse das terras originalmente indígenas foram reafirmados ainda no Brasil colônia, pela Carta Régia de 09 de março de 1718.

No intuito de diminuir a escravidão indígena e o consequente isolamento de tal povo, surge o Diretório dos Índios, elaborado em 1755 e publicado em 1757 com determinações que possibilitavam, por exemplo, a mistura e a convivência dos colonizadores brancos e missionários, permitindo o casamento entre eles e os povos originários, estipulando a língua portuguesa como oficial, além de condenar a discriminação, mas tratando o povo indígena como povo de segunda categoria, sendo aqueles que não possuem privilégios ou direitos que os demais cidadãos possuem. Tal Diretório chega a ser estendido por toda a América Portuguesa e logo após, em 1798, é revogado. Ainda, por fim, a lei Pombalina foi a última norma a tratar de direitos indígenas no Brasil Colônia e inaugurou as reformas política, econômica e social, possibilitando a garantia do direito às terras indígenas aos seus herdeiros.

Fica evidente que a preocupação das normas no período colonial se voltava para a garantia do direito à terra indígena, por serem eles seus primeiros detentores. Contudo, não existiu a efetivação dos mecanismos legais referentes ao povo supracitado e gradativamente foram saindo de contexto as determinações legais anteriormente criadas. 
Com a chegada da família Real portuguesa, em 1808, novos preceitos indígenas foram aplicados. Dentre eles, estava a permissão de escravizar índios que entrassem em conflito com os colonizadores, em um princípio aplicado por Dom João VI como "guerra justa”.

O Decreto $n^{\circ} 426$ surge em 1845, época do Brasil império, com o objetivo de regulamentar de forma efetiva a presença dos povos indígenas no Brasil, tendo como título "o regulamento acerca das Missões de Catequese e civilização dos índios" (BRASIL, 1845), em que se concedia um amparo estatal maior, além de uma assistência governamental que viabilizasse o gozo das garantias dispostas na lei. Segundo Cunha (2009, p. 139), o Decreto no 426 é o único documento a tratar sobre o povo supracitado de forma geral no Brasil império, além de possuir um teor mais administrativo do que político.

O direito à terra é colocado em pauta novamente com a Lei 601, também chamada Lei de Terras, de 18 de setembro de 1850, promulgada pelo imperador Dom Pedro II, que estipulava a necessidade de regulamentação do direito à terra de forma geral em todo o território brasileiro; todavia, houve a inclusão de uma disposição específica sobre o direito dos povos originários, como segue: “Art. 12. O governo reservará das terras devolutas as que julgar necessárias: $1^{\circ}$, para a colonização dos indígenas" (BRASIL, 1850).

A Lei de Terras foi regulamentada pelo Decreto Imperial $n^{\circ} 1.318$ de 1854, em que foi garantida a construção de aldeias direcionada aos povos indígenas e organizado o usufruto das terras; contudo, o usufruto não lhes era permitido, sendo esse direito direcionado apenas aos demais brasileiros.

Em 1973, surge a primeira lei específica a tratar dos povos indígenas: a Lei $n^{\circ} 6.001$ de 19 de dezembro 1973, também conhecida como Estatuto do Índio, que estabelece no Título I, Dos princípios e Definições:

Art. $1^{\circ}$ Esta Lei regula a situação jurídica dos índios ou silvícolas e das comunidades indígenas, com o propósito de preservar a sua cultura e integrá-los, progressiva e harmoniosamente, à comunhão nacional.

Parágrafo único. Aos índios e às comunidades indígenas se estende a proteção das leis do País, nos mesmos termos em que se aplicam aos demais brasileiros, resguardados os usos, costumes e tradições indígenas, bem como as condições peculiares reconhecidas nesta Lei (BRASIL, 1973).

Com a Lei $\mathrm{n}^{\circ} 6.001 / 73$, foram colocados no cenário nacional de forma específica os direitos dos povos indígenas com um viés de proteção cultural elevado, ao mesmo tempo em que os integrava à comunhão nacional. Tratou-se ainda sobre questões fundiárias, de saúde, patrimônio e de normas penais, bem como foi estabelecido o respeito à manutenção e desen- 
volvimento de todas as comunidades indígenas, sendo o Estatuto do Índio o principal diploma normativo a tratar de direitos indigenistas (ANJOS FILHO, 2009, p. 25).

Destarte, segundo Albuquerque (2017, p. 29), o Estatuto estabelece uma política integracionista dos indígenas à sociedade brasileira, resultando no abandono da cultura indígena e consequente aceitação dos costumes sociais dos não índios. Assim sendo, apesar de se tratar de uma legislação específica, não cuidou de atribuir autonomia necessária a tal povo. Lopes e Uchoa $(2018$, p. 17) coadunam no mesmo sentido, quando afirmam que a perspectiva assimilacionista presente no Estatuto do Índio (1973) deve ser rejeitada, haja vista desconhecer a capacidade dos povos indígenas de se autodeterminar, mantendo uma posição paternalista do Estado.

A Constituição de 1988 inova o cenário jurídico, quando imprime uma feição de sociedade plural, na busca de proteger direitos indígenas, tendo em vista a diversidade étnica existente e a constatação de convivência dos povos no território brasileiro (JOAQUIM, 2013, p. 16). Elevou-se o direito dos povos indígenas ao status de direito fundamental, consagrado e garantido no cenário nacional, além de ser afirmado por normas e diretrizes do universo internacional, também adotadas pelo Brasil.

Em suma, os primeiros mecanismos relativos à proteção de direitos indígenas não continham efetividade real de aplicação. Entretanto, com a constante evolução da sociedade global e nacional, os povos indígenas foram adquirindo espaço, sendo verificadas mudanças positivas de cunho protecionista, ainda que lentamente. Saindo do universo onde as leis tratavam apenas da posse de terras, no sentido literal, e partindo para a proteção e manutenção de seus modos e culturas, que ficam evidenciados e vão evoluindo na legislação brasileira a partir da Constituição Federal de 1934 e progridem com as seguintes Constituições até advir a Constituição Federal de 1988.

\section{O DIREITO À TERRA}

A terra para os povos indígenas ultrapassa a importância do local físico; como já visto, abrange uma relação íntima e pessoal com o povo que habita, constituindo um recurso sociocultural. A luta pela terra indígena imprime a violência, exploração, invasão, bem como discriminação sofrida pelo povo supracitado para conseguir reconhecimento de seus direitos ao longo dos séculos, acarretando uma devastação física e cultural que resultou na eliminação 
de inúmeras etnias indígenas, especialmente mediante a ruptura histórica da ligação entre os povos indígenas e as terras em que habitavam (SILVA, 2018, p. 481).

Com a superação de um pensamento evolucionista no qual os povos indígenas devem ser integrados e assimilados à comunhão nacional, seus direitos foram incluídos na Constituição Federal de 1988 e ainda em outros mecanismos legais, como a Lei 6.001/73 (Estatuto do Índio) e o Decreto $n^{\circ} 1.775 / 96$.

Desta feita, o direito dos povos indígenas sobre a terra já encontra respaldo em diversos dispositivos, que convergem no sentido de garantir-lhes direitos constitucionais inerentes. Além de serem possuidores permanentes de suas terras, a $\mathrm{CF} / 88$ determina o usufruto exclusivo das riquezas do solo, dos rios e dos lagos nelas existentes, que vai além do usufruto presente no Direito Civil, por se tratar de um direito exclusivo originário, anterior inclusive à propriedade, bem como constituindo um direito permanente que afasta a incidência de outras normas civis, como as relativas à extinção do usufruto.

De forma ampla, o direito de propriedade é definido por Álvaro Villaça Azevedo (2014, p. 38-39) como o direito que o indivíduo ou pessoa jurídica tem, em caráter próprio e exclusivo, de ter determinada coisa como parte de seu patrimônio e à sua disposição, consistindo no direito real de usar, gozar, ou fruir, dispor e reivindicar a coisa, levando em consideração todos os limites para cumprimento da sua função social. Tratando-se de terras indígenas, o regime jurídico é especialíssimo, sendo um direito coletivo dos povos originários e a propriedade das terras é da União, o que vem a facilitar a atuação de órgãos federais que auxiliam na proteção dos povos indígenas e conservação da biodiversidade.

À vista disso, resta evidente que o direito coletivo à terra do mencionado povo abrange um universo de direitos que vão além do valor físico do solo, pois abrange cultura, crenças, identidade, costumes e valores, que estão especialmente interligados com seu habitat.

A Constituição Federal de 1988 alavancou o sistema de garantias referentes aos povos indígenas quando o texto constitucional incluiu normas com o intuito de proclamar e proteger o direito dos povos originário, por tantas vezes violados. Trazendo disposições acerca de propriedade das terras, competência da União para legislar sobre povos indígenas, consagrando a relação com a terra, bem como preservando suas línguas, costumes e tradições, fica evidente o valor fundamental presente no dispositivo legal citado acima.

Destarte, o direito dos povos indígenas sobre as terras que tradicionalmente ocupam tem respaldo efetivo na $\mathrm{CF} / 88$, que restaura as concepções legais quando estabelece que tais direitos se configuram como direito coletivo e constituem natureza originária de tal povo. Tais 
determinações são anteriores à formação do Estado, ou seja, sua existência é independente de qualquer reconhecimento oficial (ISA, 2018, p. 3). Fundada no instituto do indigenato, é conceituada uma relação que vem de uma tradicional instituição jurídica luso-brasileira, em que, desde os tempos coloniais, as terras outorgadas a particulares deveriam ter reservado o direto dos povos indígenas, como primários e naturais senhores de tais terras.

A $\mathrm{CF} / 88$ eleva ao patamar constitucional o conceito de terra indígena, quando define no parágrafo $1^{\circ}$ do art. 231 :

São terras tradicionalmente ocupadas pelos índios as por eles habitadas em caráter permanente, as utilizadas para suas atividades produtivas, as imprescindíveis à preservação dos recursos ambientais necessários a seu bem-estar e as necessárias à sua reprodução física e cultural, segundo seus usos, costumes e tradições (BRASIL, 1988).

A definição de terra trazida pelo texto constitucional contém elementos que, quando reunidos, traduzem usos, costumes e tradições do determinado povo e, à medida que são apurados, o direito à terra se legitima de forma independente de qualquer ato constitutivo.

Após determinar o direito originário sobre as terras que tradicionalmente, o art. 231 da $\mathrm{CF} / 88$ ainda inclui determinações de valor substancial para a população indígena, como por exemplo, a posse permanente e o usufruto exclusivo das riquezas do solo, rios e lagos existentes nas terras indígenas. Tal determinação consegue imprimir a importância que às terras indígenas carregam, quando acrescenta também que as mesmas são inalienáveis, indisponíveis, ou seja, tais terras não podem ser alienadas, alugadas, vendidas ou arrendadas, nem pelos povos indígenas, nem pela União.

Ademais, os direitos sobre as terras em apreço são imprescritíveis, ao passo que não são atingidos por decurso de prazo e/ou consumação de situações opostas ao direito garantido, sendo nulo e extinto qualquer ato que tenha por objeto a ocupação, o domínio e a posse das terras supracitadas. É vedada ainda a remoção do povo indígena de suas terras, salvo casos excepcionais e temporários (BRASIL, 1988).

No cenário internacional, a convenção 169 da Organização Internacional do Trabalho (OIT) sobre Povos Indígenas e Tribais trouxe maiores avanços para o reconhecimento de direitos econômicos, sociais e culturais de tais minorias. A relação especial que os povos indígenas têm com sua terra é reafirmada pela Convenção, determinando ainda a consulta prévia, livre, informada e de boa-fé aos povos originários quando necessária a tomada de decisões legislativas ou administrativas que possam afetá-los diretamente. É necessário que os povos indígenas externem se aceitam ou não as modificações em suas condições de vida, bem como 
importa verificar a boa-fé em todas as fases de consulta, possibilitando o entendimento correto e tempo necessário para análise das questões levantadas acerca da terra (SOUZA FILHO, 2018, p. 176).

Tais garantias visam a acrescer a proteção do direito dos povos indígenas ao seu território, tendo em vista que o histórico de massacres, violências e remoção do povo de sua terra traduz a necessidade do estado em se mostrar ativo para efetivar os direitos presentes nos dispositivos legais constitucionais e infraconstitucionais, embora mesmo com a positivação de tais normas ainda seja corriqueiro atos de violência e discriminação com o povo que é tido como minoria em estado de vulnerabilidade.

O texto constitucional cuida da posse dos povos indígenas sobre as terras que tradicionalmente ocupam como sendo uma posse permanente, em que a noção de posse é entendida como habitat. Não se trata simplesmente da posse regulada pelo Direito Civil, com características limitadas.

Desta feita, as terras indígenas são reconhecidas pelo Estado por meio da demarcação, cujo processo é disciplinado pelo Decreto $\mathrm{n}^{\mathrm{o}} 1.775 / 96$, que se externa de forma meramente declaratória, tendo em vista o seu direito originário. O objetivo do diploma em apreço consiste apenas em determinar a extensão do local objeto da posse permanente indígena, para que seja possível assegurar a plena eficácia do texto constitucional, cabendo à União a obrigação de determinar e proteger tais terras, tendo em vista que fazem parte de seus bens, conforme determina o art. 20, XI da $\mathrm{CF} / 88$.

Convém mencionar ainda que foi fixado nas Disposições Constitucionais Transitórias o prazo de cinco anos para que todas as terras indígenas no Brasil fossem demarcadas. Entretanto, tal determinação não foi cumprida, sendo a demarcação de terras indígenas ainda um assunto atual e pendente de apreciação do Estado brasileiro, haja vista conflitos de interesses entre povos indígenas e não índios localizados em terras originárias indígenas, muitas vezes com títulos de propriedade privada regulados pelo Direito Civil brasileiro anteriores à $\mathrm{CF} / 88$.

Os civilistas sempre buscaram a melhor forma de conceituar a propriedade. Carlos Roberto Gonçalves (2019, p. 223) constrói seu conceito como sendo aquele direito "mais completo dos direitos subjetivos, a matriz dos direitos reais e o núcleo do direito das coisas". Ao tratar do termo "propriedade", Paulo Lôbo (2015, p. 85) assegura que tanto serve para expressar o direito de propriedade propriamente dito como um poder jurídico que determinada pessoa detém sobre a coisa de forma subjetiva, quanto para refletir o direito de propriedade na coisa objeto de tal direito, de forma objetiva. Entretanto, o autor menciona que o termo "direi- 
to de propriedade" deve se restringir àqueles que detenham o título formal reconhecido pelo direito aquisitivo da coisa.

Na legislação brasileira, os limites referentes ao direito de propriedade têm o objetivo de resguardar a efetividade do princípio da dignidade da pessoa humana, tendo em vista ter sido elevado ao status de direito fundamental, quando do cumprimento de sua função social, conforme determina o art. $5^{\circ} \mathrm{XXIII}$ da $\mathrm{CF} / 88$. Por tais razões, o CC/02 tratou a propriedade de forma harmônica com a Lei Fundamental, segundo os ditames de seu art. 1.228:

Art. 1.228. O proprietário tem a faculdade de usar, gozar e dispor da coisa, e o direito de reavê-la do poder de quem quer que injustamente a possua ou detenha. $\S 1^{\circ} \mathrm{O}$ direito de propriedade deve ser exercido em consonância com as suas finalidades econômicas e sociais e de modo que sejam preservados, de conformidade com o estabelecido em lei especial, a flora, a fauna, as belezas naturais, o equilíbrio ecológico e o patrimônio histórico e artístico, bem como evitada a poluição do ar e das águas [...] (BRASIL, 2002).

Fica evidente que a propriedade hoje não é mais considerada um direito ilimitado, como consagrada no passado, mas sim um importantíssimo direito real que deve levar em conta, a todo o momento, o seu aspecto funcional (GAGLIANO, 2018, p. 1046). São diversos os tipos de propriedade, como a propriedade pública, social, privada, agrícola, etc. Após análise de seus respetivos conteúdos, suas limitações, função social, bem como formas de aquisição e perda de propriedade, ganham especificações que determinam a disciplina a ser seguida.

As terras indígenas são bens de uso especial ou sui generis, condicionada aos limites do art. 231 da $\mathrm{CF} / 88$, e propriedade da União, entretanto possuem uma regulação específica retirada da interpretação da Constituição. Embora as terras indígenas façam parte do rol dos bens da União (art. 20, XI), este ente público comporta genericamente os direitos de gozo e fruição, cabendo apenas e exclusivamente aos povos indígenas a utilização de tais terras, por meio dos institutos da posse permanente e do usufruto exclusivo, haja vista serem os detentores do direito originário sobre as terras, direito este de natureza coletiva e não individual, tendo a União propriedade a título derivado.

Desse modo, a propriedade abrange um universo de direitos e não é apenas um regime jurídico do Direito Civil, mas sim de um complexo de normas que rodeiam o meio constitucional, urbano, administrativo, civil e ambiental. Restam evidentes os motivos pelos quais se trata de um direito complexo, bem como importante e substancial a pesquisa para entender as diretrizes legais que regulam a propriedade. 
Nos termos do art. 20, XI da CF/88, a União é a proprietária das terras indígenas, tratando-se, segundo parte da doutrina, de um bem público afetado aos interesses do estado brasileiro. Em se tratando de terras indígenas, falamos em um direito coletivo, sendo a posse destinada aos povos indígenas de forma permanente, a qual é exercida mediante o usufruto exclusivo, conforme reza o art. $231, \S 2^{\circ}$ da $\mathrm{CF} / 88$.

A ideia da posse indígena é tratada de forma diferente da visão tradicional posta no âmbito do Direito Civil, pois aí se concebe a posse como uma ius possidendi, uma forma de exteriorização do domínio que traduz o direito de possuir o que é seu, tendo como uma consequência lógica o usufruto exclusivo, que também difere do presente no Código Civil brasileiro, ao passo que se trata de um modo de exercício do domínio.

Assim, Savigny e Ihering, em suas teorias tradicionais de posse, não refletem de modo adequado a concepção da posse indígena estipulada no $\mathrm{CF} / 88$, além de não traduzir de maneira satisfatória as justificativas que são exibidas na aplicação dos institutos clássicos (FERNANDES, 2016, p. 30). As determinações presentes no CC/02 são mais bem interpretadas quando auxiliadas pela $\mathrm{CF} / 88$, principalmente quando o direito do qual se trata tem respaldo em norma constitucional fundamental, com o fito de garantir o melhor desenvolvimento da sociedade nacional, protegendo seus espaços e valores.

Com relação ao usufruto, o art. 1.390 do CC/02 determina que "pode recair em um ou mais bens, móveis ou imóveis, em um patrimônio inteiro, ou parte deste, abrangendo-lhe, no todo ou em parte, os frutos e utilidades" (BRASIL, 2002). Pablo Stolze Gagliano (2004. p. 122), ao discorrer sobre o instituto do usufruto, menciona que tal direito real pode ser estabelecido por diversas maneiras: negócio jurídico gratuito ou oneroso, testamento, usucapião e por força de lei.

Importante ressaltar que, de forma semelhante à propriedade, o usufruto de imóveis também exige o registro em Cartório, conforme reza o art. 1.391 do Código Civil: "o usufruto de imóveis, quando não resulte de usucapião, constituir-se-á mediante registro no Cartório de Registro de Imóveis.” (BRASIL, 2002).

Destarte, quando tratamos dos direitos indígenas, a posse permanente e o usufruto exclusivo são determinados de forma especial pela $\mathrm{CF} / 88$, que não trata dos institutos supracitados de forma convencional, possuindo uma interpretação extensiva e protecionista dos povos nativos brasileiros, haja vista tratar-se de um direito coletivo e fundamental para os povos originários. 
A terra indígena não constitui apenas um simples objeto de direito coletivo; é entendida, em verdade, no íntimo das comunidades indígenas como parte de sua vida, princípios e crenças, resumindo em si toda a ancestralidade e posterioridade das etnias. Por esta razão, a $\mathrm{CF} / 88$ proíbe a remoção dos povos indígenas das terras que ocupam tradicionalmente, reconhecendo sua posse permanente e seu usufruto exclusivo, afirmando que as terras "são inalienáveis e indisponíveis, e os direitos sobre elas, imprescritíveis", conforme precisa o $\S 4^{\circ}$ do art. 231 da $\mathrm{CF} / 88$.

$\mathrm{O}$ instituto da posse e do usufruto no $\mathrm{CC} / 02$ não consagra os direitos do povo supramencionado porque, neste caso, trata-se de determinação constitucional especial direcionada aos povos nativos. Não se trata de privilégio que pode ser suprimido pelo Estado ou ainda superado por títulos de propriedade privada de terceiros, mas sim um direito coletivo originário de possuir e usufruir de forma permanente e exclusiva tais terras.

A demarcação das terras indígenas, regida pelo Decreto $n^{\circ} 1.775 / 96$ e que tem efeito declarativo, não constituindo direitos, é o meio administrativo para identificar e sinalizar quais os limites que constituem o território ocupado tradicionalmente pelos indígenas, preservando as terras e organizando o espaço no intuito de efetivar as garantias dispostas na CF/88.

Embora o direito dos povos indígenas sobre suas terras constitua um direito originário, elencado na $\mathrm{CF} / 88$, muitas são as alegações que se contrapõem a tal direito, bem como sua demarcação definitiva, como: a invasão por não índios, a compra da terra pelo instituto do CC/02, a posse de agricultores, o desenvolvimento econômico, a ausência de índios, etc. Entretanto, a constatação da inexistência de posse iminente dos povos indígenas sobre as terras originárias não exclui o direito destes sobre as terras, nem tampouco as transforma em terras particulares ou devolutas.

Ao contrário disto, quando determinada área for comprovada como terra indígena, providências suficientes devem ser tomadas para que o povo detentor de tal terra tenha seu direito reestabelecido, tendo em vista ser de conhecimento geral os fatos que demonstram reincidentes casos de expulsão dos povos indígenas de suas terras, motivo pelo qual diversas comunidades indígenas saem do seu habitat para preservar sua vida e necessitam do amparo estatal na restituição de seus direitos (SOUSA, 2012, p. 71).

A demarcação das terras indígenas tradicionalmente ocupadas no Brasil acontece por meio de processo administrativo, o qual é definido por meio de Decreto da Presidência da República, dividido em fases para melhor organização dos procedimentos. 
A primeira fase do processo administrativo de demarcação das terras originárias consiste na elaboração de um estudo, em que pesquisas antropológicas, ambientais, fundiárias e cartográficas são utilizadas como fundamento para a identificação e delimitação do espaço físico da terra indígena. Na sequência, encaminha-se para a delimitação, quando as terras estudadas e aprovadas têm sua conclusão publicada no Diário Oficial da União e do Estado, para que se proceda decisão acerca da expedição da Portaria Declaratória de posse indígena. Após a expedição da Portaria, anteriormente citada pelo Ministro da Justiça com a autorização para demarcação física, bem como a materialização do espaço e georreferenciamento, as terras são consideradas já declaradas.

Assim, após declaradas, as terras são homologadas quando já materializados os limites das terras e o georreferenciamento, em que a demarcação já fora homologada por decreto Presidencial. Ato contínuo, são classificadas como regularizadas, logo após serem registradas em Cartório e na Secretaria do Patrimônio da União. Por fim, para a proteção de comunidades e povos indígenas isolados, as áreas podem ser interditadas, com restrições de uso e ingresso de terceiros (FUNAI, 2019, p. 1).

As fases descritas acima nem sempre seguem a sequência lógica e contínua dos fatos, existindo recursos judiciais e disputas por proprietários, agricultores e outros, que buscam conseguir a garantia de utilizar tais terras. Desse modo, ainda que seja realizada a demarcação das terras indígenas, os processos de efetivação e liberação das terras para o seu povo são lentos e tornam-se cada vez mais dispendiosa para todas as partes, tendo em vista ser frequente o desrespeito dos limites impostos pelo processo de demarcação, sendo configurado como crime, ao passo que se invade área de patrimônio da União a ser protegido (PENA, 2019, p. 3).

Para assegurar a sobrevivência das comunidades indígenas no país, com a devida manutenção de seus costumes, crenças, hábitos e identidade, é necessário que haja o reconhecimento oficial dos limites territoriais e de sua natureza, sendo primordial a garantia da segurança do local em que fazem morada, espaço que possui íntima e profunda relação espiritual com os povos indígenas.

Com base no exposto, fica evidente a relevância da demarcação das terras, tanto para os povos indígenas quanto para a sociedade brasileira, haja vista o interesse em reconhecer a organização social e as atividades indígenas, para alcançar a autonomia e autodeterminação dos povos indígenas no Brasil, na busca de construir de fato um estado democrático e pluriétnico. 
Os procedimentos de demarcação e regularização das terras indígenas, todavia, deveriam ser realizados em tempo hábil, respeitados os limites e as determinações legais, para que os direitos indígenas fossem resguardados e consequentemente fosse diminuída a quantidade de processos judiciais acerca do conflito de interesses sobre as terras.

Sobre a demarcação das terras indígenas, ademais, convém mencionar a Medida Provisória (MP) nº 870, de 2019 que "estabelece a organização básica dos órgãos da Presidência da República e dos Ministérios, definindo suas competências e sua estrutura básica". Tal norma estava transferindo, no seu texto original de publicação, a demarcação das terras indígenas para o Ministério da Agricultura, bem como transferindo a Funai do Ministério da Justiça e Segurança Pública para o Ministério da Mulher, da Família e dos Direitos Humanos. Ao realizar tais mudanças, a medida provisória colocou em conflito interesses dos povos indígenas com política agrícola da União, com prejuízo para os povos originários.

Segundo nota técnica $n^{\mathrm{o}}$ 1/2019-6 $6^{\mathrm{a} C C R}$, do Ministério Público Federal, ao realizar a transferência supracitada, a MP desvaloriza e recusa a distinção entre o desenvolvimento dos povos indígenas e dos não indígenas, existente na própria $\mathrm{CF} / 88$ e reafirmada diversas vezes em julgamentos anteriores pelo Supremo Tribunal Federal.

Tal transferência traz à tona uma reformulação de uma política integracionista, assimilacionista já superada pela Carta Magna, além de ser causa de exorbitantes violações dos direitos dos povos indígenas no século passado. Retorna-se o fato de que os povos indígenas devem ser integrados à comunhão nacional, abdicando de seus princípios tradicionais para compor a sociedade de trabalhadores rurais que se conectam mediante uma política agrícola, obviamente focalizada para não índios. Com efeito:

\begin{abstract}
A MP $n^{\circ} .870 / 2019$, ao retirar da Funai a competência para realizar os estudos para demarcação de terras indígenas, transferindo a matéria para o Ministério da Agricultura, Pecuária e Abastecimento, inviabilizou a promoção de uma política ambiental que respeite a convergência entre o usufruto exclusivo das terras indígenas e a preservação do meio ambiente nesses territórios, o que implica retrocesso repudiado pelo sistema da Constituição, como já afirmou o STF na ADI nº 4717 (BRASIL, 2019, p. 14).
\end{abstract}

Com o decorrer da tramitação da MP 870/2019, a comissão mista realizou mudanças no texto legal que foram mantidas pelo plenário, entre elas, a volta da Funai ao Ministério da Justiça e Segurança Pública. A medida provisória foi transformada em norma jurídica com veto parcial, qual seja a lei no 13.844 de 18/06/2019. 
Fica evidente que as questões sobre direitos indígenas fazem parte da pauta nacional atual, ficando claro que é de suma importância preservar o direito do povo originário do país, inclusive contra ações do próprio Estado que visem a diminuir ou inferiorizar um povo, por ser minoria vulnerável no país, mas com direito de se autodeterminar e defender seus preceitos. Demarcar as terras indígenas é uma forma de respeitar os seus povos e conceder a manutenção de seus princípios. Embora muitos sejam os obstáculos, é de fundamental importância a realização dos procedimentos administrativos, como a demarcação das terras, embasados nos direitos fundamentais, para que seja possível efetivar as normas que possibilitam a subsistência do povo nativo brasileiro e sua autoafirmação, excluindo o interesse em integrá-los a uma cultura já determinada.

\section{O CONFLITO RELATIVO AOS DIREITOS ORIGINÁRIOS INDÍGENAS E O DIREITO À PROPRIEDADE PRIVADA DOS NÃO INDÍGENAS}

Diante de tudo que foi abordado acerca das terras indígenas, encontra-se um impasse na sociedade Brasileira quando nos deparamos com o registro civil de terras originalmente indígenas, terras essas que muitas vezes foram registradas antes do advento da $\mathrm{CF} / 88$. Ocorre então um conflito entre o que preceitua a Constituição, quando determina em seu art. 231 que compete à União demarcar as terras que os povos indígenas tradicionalmente ocupam, e o que acontece na prática, uma vez que as propriedades indígenas não se encontram demarcadas em sua totalidade, ocasionando um impasse no momento em que particulares adquirem terras e as registram civilmente.

É fácil perceber o choque que ocorre quando indivíduos não indígenas buscam amparo estatal e jurídico diante de conflitos na justiça por terras que foram registradas por particulares, mas que pertencem originalmente aos povos indígenas, que detêm direito coletivo sobre tais terras. Vale mencionar aqui que o fato de a União não demarcar todas as terras indígenas não autoriza que se trate a mesma como propriedade privada, uma vez que o direito à propriedade indígena transcende a esfera cível, tratando-se de direito assegurado constitucionalmente, mas que antecede a própria $\mathrm{CF} / 88$.

É justamente nesse cenário que se vislumbram disputas de particulares junto ao Judiciário, em relação a acrescer terras originalmente indígenas, mas registradas e muitas vezes utilizadas há anos por particulares. 
Um Acórdão da Quarta Turma do Tribunal Regional Federal, no Agravo de Instrumento n. 0805973-62.2016.4.05.0000, concedeu reintegração de posse de um imóvel localizado na Estrada do Garrote (Caucaia/CE) às empresas STG Construções Imobiliária Ltda. e Cabatan Incorporadora SPE Ltda. Ocorre que a Funai ajuizou, em 13 de fevereiro de 2017, Agravo Regimental na Suspensão de Liminar, com o objetivo óbvio de suspender os efeitos de tal liminar, a fim de tentar preservar o direito das terras indígenas. A decisão foi registrada sob a seguinte ementa:

EMENTA: AGRAVO REGIMENTAL NA SUSPENSÃO DE LIMINAR. AÇÃO DE REINTEGRAÇÃO DE POSSE. IMÓVEL RURAL. OCUPAÇÃO INDÍGENA TRADICIONAL. ORDEM DE RETIRADA DA COMUNIDADE INDÍGENA TAPEBA. ESTUDO ANTROPOLÓGICO. FUNAI. PROCEDIMENTO DEMARCATÓRIO PENDENTE. RELATÓRIO CIRCUNSTANCIADO DE REVISÃO DE LIMITES. RISCO DE LESÃO À ORDEM E À SEGURANÇA PÚBLICAS. AGRAVO AO QUAL SE NEGA PROVIMENTO. (STF- AgR SL: 1096 CE - CEARÁ, Relator(a): Min. CÁRMEN LÚCIA (Presidente), Tribunal Pleno, julgado em 10/09/2018, PROCESSO ELETRÔNICO DJe-202 DIVULG 24-09-2018 PUBLIC 25-09-2018).

O Acórdão que concedeu a reintegração de posse às empresas o fez sob o argumento de que não estavam presentes elementos concretos que assegurassem que aquele território pertencia aos indígenas, além de não aplicar a vedação que consta no art. 19, §2 ${ }^{\circ}$ do Estatuto dos Índios. No voto condutor, ainda se afirma que o terreno que estiver sob processo de demarcação deve ser preservado até que se conclua o feito demarcatório. Dessa forma, determinou que fosse reestabelecido o estado anterior do terreno. O Agravo foi negado, mantendo-se a decisão que concedeu a reintegração de posse.

Enxergamos o conflito presente quando tratamos de conceitos como o da posse, tendo em vista que o $\mathrm{CC} / 02$ rege tal instituto nas relações privadas, como é o caso das empresas STG Construções Imobiliária Ltda. e Cabatan Incorporadora SPE Ltda, que possuem o título de propriedade registrada em cartório, mas se deparam com uma situação ímpar, em que o seu direito é contraposto a direitos indígenas, coletivos e originários.

A Constituição garante aos povos indígenas, como direito fundamental, a posse permanente e usufruto exclusivo de propriedades originalmente indígenas, consoante já verificado. O problema reside justamente nas terras que ainda não foram demarcadas, e, embora seja a demarcação de um direito apenas de cunho declaratório, ou seja, que não tem o condão de constituir direito, essa não demarcação das terras ocasiona um desajuste territorial, uma vez 
que particulares adquirem propriedades, sem a ciência da pertença daqueles territórios à União.

Ocorre que o CC/02 garante aos proprietários, tratando-se de um direito privado, conforme reza o art. 1.228, "a faculdade de usar, gozar e dispor da coisa, e o direito de reavê-la do poder de quem quer que injustamente a possua ou detenha", condicionando-a apenas no $\S 1^{\circ}$ do mencionado dispositivo ao cumprimento de sua função social.

Se de um lado o CC/02 estabelece garantias de propriedade aos particulares que adquirem terras, de outro a $\mathrm{CF} / 88$, em seu art. 231, reconhece aos povos indígenas os direitos originários sobre as terras que originalmente ocupam; ademais, o texto normativo deixa claro que compete à União demarcar tais terras, proteger e fazer que sejam respeitados todos os bens pertencentes aos povos indígenas.

Sabe-se que os direitos conferidos aos povos indígenas são de caráter originário, mas não se pode negar que diversos são os elementos que se contrapõem à efetivação desses direitos. Ora, a invasão de terras indígenas por não índios, o avanço da economia que acaba por alastrar-se, a violência, a ausência cada vez maior dos povos indígenas e a ocorrência de compra de terras seguindo os ritos ditados pelo Código Civil fazem com que, cada vez mais, os povos originários vejam sua identidade ruir diante dos olhos.

Apesar disso, a ausência da demarcação não muda o fato de que as terras originalmente ocupadas por povos indígenas a eles pertencem. Como já vimos, trata-se de uma ação declaratória, que não origina nenhum direito, apenas o reconhece e declara. Diversos são os julgados nos tribunais a respeito da temática aqui estudada, não são poucos os casos em que o conflito de interesse entre particulares e a União é levado para apreciação junto ao Judiciário.

Em agosto de 2017 o Plenário do Supremo Tribunal Federal julgou improcedentes os pedidos de indenização ajuizados nas Ações Cíveis Ordinárias 362 e 366 . A primeira cobrava uma posição pela demarcação do Parque Nacional do Xingu, desde o ano de 1986, enquanto a segunda exigia uma reparação no que diz respeito as demarcações ocorridas nas Reservas Nambikwára e Parecis desde o ano de 1987. O Estado do Mato Grosso alegava que as terras em questão haviam sido incluídas em área indígena de maneira ilícita, pertencendo ao Estado, pois quando demarcadas não haveria ocupação indígena; no entanto, o pedido foi rejeitado por unanimidade no Plenário.

O relator do Acórdão na ACO 362 e na ACO 366, Ministro Marco Aurélio, sustentou que não havia a necessidade de indenização em nenhum dos casos, por ser a terra pertencente à União, historicamente ocupada pelo povo indígena. Ademais, laudos antropológicos perici- 
ais foram juntados aos processos comprovando a presença histórica dos povos indígenas na região objeto da lide.

Conforme consta no processo, existe laudo antropológico elaborado em 1987 pela professora Bruna Franchetto, a detalhar historicamente a presença dos indígenas naquela região do Parque Indígena do Xingu. Nas palavras do relator, "o laudo não deixa dúvidas sobre a histórica ocupação de silvícolas na área em jogo.” (BRASIL, 2017, p. 12). Ele ainda cita um laudo juntado aos autos da ACO 362 e produzido por João Dal Poz Neto, no qual há detalhada análise e constatação da presença de indígenas pela extensão da região do Rio Xingu. Nesse laudo, há referência a estudos que comprovam a ocupação indígena há no mínimo 800 anos. Nas palavras do relator "As observações do Estado autor não têm o efeito de afastar as conclusões do último laudo (...)” (BRASIL, 2017, pg. 13).

Nos autos da ACO 366, há um laudo pericial do antropólogo Rinaldo Sérgio Vieira Arruda, onde se constata que a primeira referência no que diz respeito à existência de povos indígenas Paresi datam de 1553. O Ministro sustentou não restarem dúvidas de que a presença indígena na região de que trata a inicial, perpassou os séculos incessantemente. Veja-se a ementa:

INDENIZAÇÃO - ESTADO - TERRAS INDÍGENAS. Comprovada a histórica presença indígena na área, descabe qualquer indenização em favor do Estado. (ACO 362, Relator: Min. MARCO AURÉLIO, Tribunal Pleno, julgado em 16/08/2017, ACÓRDÃO ELETRÔNICO DJe-225 DIVULG 02-10-2017 PUBLIC 03-10-2017).

Já em Acórdão proferido em sede de Apelação Cível $\mathrm{n}^{\mathrm{o}}$ 500351713.2014.4.04.7202/SC pelo Tribunal Regional Federal da $4^{\mathrm{a}}$ Região, em processo que particulares moveram contra a Funai, a fim de obterem indenização por benfeitorias feitas em área indígena já demarcada, o relator Des. Federal Ricardo Teixeira do Valle Pereira sustentou seu voto no sentido da negativa de provimento à Apelação Cível interposta. A área em questão trata-se da terra indígena Toldo Imbu, localizada no município de Abelardo Luz/ SC, sobre a qual os particulares, autores da ação, alegam que houve boa-fé quanto às benfeitorias acrescentadas no trecho demarcado.

No entanto, como afirma o relator, existe um marco temporal que serve de base para a determinação ou não do uso da boa-fé, que seria a data da publicação da portaria de demarcação, pois é a partir dessa data que se supõe que há, por parte da sociedade como um todo, o conhecimento daquele processo demarcatório, não podendo o particular alegar desconheci- 
mento de causa. O próprio procedimento prático para demarcação das terras, que ocorre antes da publicação da portaria, acontece de maneira notória e de fácil percepção para todos.

Observe-se, no caso em deslinde, que os particulares possuíam documento de compra e venda simples, repleto de falhas e insubsistente, uma vez que sequer continha o endereçamento correto do imóvel e apresentava qualificação genérica, em que sequer constava a assinatura do vendedor do imóvel, mas apenas dos compradores e de duas testemunhas. O contrato de compra e venda data de 2009 e a demarcação das terras data de abril de 2007. Dessa maneira, é duvidoso crer que os autores da ação adquiriram esse imóvel sem a ciência de que se tratava de território indígena demarcado.

Nesse sentido, o voto do relatou seguiu negando provimento ao pedido de indenização, uma vez que não era plausível a ideia de que os particulares realmente adquiriram o imóvel sem observar que aquela era uma área pertencente à União, ignorando totalmente o que dispõe o Código Civil a respeito dos vícios ou obstáculos na aquisição da coisa, eis que o art. 1.201 do CC preconiza que "é de boa-fé a posse, se o possuidor ignora o vício, ou o obstáculo que impede a aquisição da coisa" (BRASIL, 2002).

A boa-fé só poderia ser alegada até a data da portaria que demarcou as terras, após isso, tem-se que é de conhecimento geral a pertença das terras aos indígenas, a quem é assegurado o direito de usufruto exclusivo das riquezas naturais.

O relator, Des. Federal Ricardo Teixeira do Valle Pereira, menciona em seu voto ainda que as provas testemunhais colhidas no processo fortalecem o entendimento de que não houve boa-fé dos particulares, autores da ação de indenização pelas benfeitorias. Uma das testemunhas relatou que era de conhecimento público o processo de demarcação das terras indígenas, sinalizando inclusive que o ingresso dos particulares ocorreu após a demarcação do território indígena. Foi com base nisso que se negou provimento à apelação interposta. Vejamos a ementa: 
veracidade e legitimidade. (TRF4, AC 5003517-13.2014.4.04.7202, TERCEIRA TURMA, Relator RICARDO TEIXEIRA DO VALLE PEREIRA, juntado aos autos em 28/04/2016).

Diante de casos assim, percebe-se que é realidade a árdua disputa pelas terras indígenas. A demarcação das terras acaba sendo uma garantia no plano prático, uma vez que a sua ausência vem causando conflitos entre particulares e os sujeitos de garantias constitucionais às terras, como é o caso dos povos originários, conforme o que se constata após a análise de alguns casos, que representam uma pequena porção da imensa demanda judicial acerca do problema em questão.

Em acórdão proferido pelo Desembargador Federal Maurício Kato em sede de apelação no Tribunal Regional Federal da $3^{\text {a }}$ Região, foi negado provimento à apelação interposta pelo Município de Vicentina, que tinha por objetivo a declaração judicial de que as terras por eles ocupadas, que tinham titulação datada de antes da $\mathrm{CF} / 88$, não poderiam ser consideradas terras indígenas nem estudadas em processo de demarcação.

O relator manteve a sentença, asseverou que a demarcação das terras indígenas não passa de um ato declaratório, não sendo possível barrar o processo demarcatório, sustentado apenas em direito possessório, uma vez que os atos administrativos que formam o processo de demarcação estão amparados pela Constituição e gozam de presunção de legitimidade, não sendo cabível, sequer, a ação de interdito possessório contra a demarcação, nas palavras do relator (BRASIL, 2018, p. 3).

O relator faz menção ainda, ao que preceitua o art. $2^{\circ}, \S 8^{\circ}$, do Decreto $n^{\circ} 1775 / 96$, que assegura aos interessados o contraditório. Sendo assim, o Município e demais interessados possuíram prazo para manifestar-se ao órgão federal de assistência ao índio, as razões devidamente fundamentadas e aparadas por laudos, estudos, imagens, declarações de testemunhas etc., para demonstrar o cabimento de indenização ou até mesmo para demonstrar vícios porventura existentes no processo demarcatório. Ocorre que isso não foi feito e findo o prazo para arguir-se tais provas, tornou-se obsoleta a reclamação do autor da ação. (BRASIL, 2018, p. 3)

Assim, o relator do acórdão alegou que houve momento adequado para manifestação dos interessados em participarem do procedimento de demarcação das terras, o que não aconteceu, pois o pedido autoral ultrapassava essa linha de acompanhamento no processo demarcatório. Ora, o que se buscou com o ajuizamento da ação em questão foi a declaração de imu- 
nidade de terras que não estivessem ocupadas pelos povos indígenas na data de 05.10.88, e que já haviam sido tituladas anteriormente a essa data.

Aqui fazendo referência ao marco temporal fixado pelo STF no caso Raposa Serra do Sol, em que foi adotada a teoria do fato indígena, usando como referência a data da promulgação da Constituição da República de 1988 para inferir sobre a ocupação geográfica, o relator afirma não ser cabível esse entendimento no caso em questão, pois o pleito "mostra-se genérico e abstrato, violando a previsão dos artigos 322 e 324 do Código de Processo Civil”" (BRASIL, 2018, p. 3) que assevera que o pedido deve ser certo e determinado, e não o sendo, inviabiliza até mesmo a análise e julgamento do mérito.

A pretensão do autor é imprópria, por não objetivar a observância do que consta no Decreto $n^{\circ} 1775 / 96$, mas sim, desejar provimento jurisdicional no sentido de declarar de maneira geral que as terras localizadas no território do município do autor que tenham titulação anterior à $\mathrm{CF} / 88$ não sejam objeto de estudo para demarcação. Vejamos a ementa:

\begin{abstract}
PROCESSO CIVIL. DEMARCAÇÃO. TERRAS INDÍGENAS. MUNICÍPIO. 1. A demarcação de terra indígena constitui ato formal, de natureza declaratória, que tem por escopo o reconhecimento de um direito pré-existente (originário). Trata-se de ato administrativo que goza de presunção de legitimidade e veracidade (presunção juris tantum), cabendo à parte contrária impugná-lo, mediante a apresentação de provas inequívocas, aptas a infirmá-lo. 2. A legislação assegura a efetiva participação e contraditório aos entes envolvidos e demais interessados, em momento adequado, no procedimento administrativo-demarcatório. 3. A pretensão do Autor não consiste em buscar a efetiva observância dos termos do Decreto $\mathrm{n}^{\mathrm{o}}$ 1.775/96 e dos comandos constitucionais que disciplinam a matéria, mas sim em obter, desde logo, provimento jurisdicional que declare, genericamente, que as propriedades compreendidas no âmbito dos limites territoriais do município autor, cuja titulação seja anterior à promulgação da Constituição da República de 1988, não poderão ser consideradas terras indígenas e tampouco objeto de estudos para demarcação, pretensão esta descabida. 4. Apelação do Município de Vicentina desprovida. (TRF-3 - Ap: 00003289220104036002 MS, Relator: DESEMBARGADOR FEDERAL MAURICIO KATO, Data de Julgamento: 05/03/2018, QUINTA TURMA, Data de Publicação: e-DJF3 Judicial 1 DATA:12/03/2018).
\end{abstract}

Diante dos casos aqui mencionados, vislumbra-se de maneira mais prática o que realmente ocorre com esses territórios indígenas. Apesar de termos a demarcação como ato meramente declaratório, sua não realização acaba por facilitar que particulares registrem as terras como sendo suas e de acordo com os ditames constantes no Direito Civil. Nas palavras de Elizângela Cardoso de Araújo Silva (2018, pg. 498), “a aceitação social de que as terras indígenas são 'direitos originários', ou seja, antecedem a criação do próprio Estado brasileiro, é fundamental para os processos de demarcação".

Infelizmente, ainda há resistência da sociedade como um todo nesse sentido, além do descuido e/ou desinteresse demonstrado pelo Estado de garantir e efetivar as disposições 
Constitucionais Fundamentais relativas aos direitos de povos indígenas, direitos estes inerentes a sua qualidade. Nesse ponto encontramos um conflito entre o que preceitua a Constituição Federal e o que está disposto no Código Civil sobre propriedade.

É importante que a sociedade volte o olhar para os povos indígenas, não como povos inferiores que precisam evoluir para adequar-se a uma sociedade imposta pela maioria. Apesar de estarmos nos referindo a uma minoria que se encontra em estado vulnerável, não podemos nos esquecer ou negligenciar o fato de tratar-se de povos que carregam consigo a história do Brasil, e que merecem o olhar cuidadoso, que busque efetivar sua proteção, de acordo com os ditames constitucionais.

\section{CONCLUSÃO}

A luta indígena por territórios antecede a criação do Estado brasileiro. Os povos indígenas foram vítimas de grande violência e exploração de sua mão-de-obra desde o período colonial. Passando por diversas tribulações, o mencionado povo se manteve firme em resistir às afrontas estatais e sociais para conservar sua identidade, seus costumes, crenças e cultura, frente a uma sociedade com interesses assimilacionistas outrora superados, mas reincidentes no cenário nacional atual.

As determinações acerca dos povos indígenas e seus direitos foram sendo colocadas em pauta de forma gradativa, mediante muita luta e resistência, ao passo que se introduzia no seio local mecanismos legais e órgãos de apoio e auxilio a questões relativas ao mencionado povo, com intuito de resguardar os povos historicamente excluídos, como por exemplo a Lei $n^{0}$ 6.001/73 (Estatuto do Índio) e a Funai. Já a Constituição Federal de 1988 mostrou ter um cuidado particular com o povo nativo, quando incorporou no seu texto legal normas fundamentais que visam garantir e efetivar a aplicação e a proteção dos direitos indígenas, em especial, o seu direito à terra, para manter a posse permanente e o usufruto exclusivo, consagrado como um direito coletivo originário e anterior ainda a instituição do Estado brasileiro, deixando evidente o valor fundamental que a presente lei carrega.

Ao tratarmos de terras, institutos como o da propriedade, posse e usufruto, regidos pelo Código Civil brasileiro, de natureza individual/privada, são utilizados por não índios para reger situações entre particulares. Entretanto, a entrega a títulos de propriedade a não índios, não poderia surtir efeitos legais, quando o território em questão se tratasse de terras originárias indígenas, tendo em vista não ser um espaço disponível à alienação privada. 
Destarte, é clara a quantidade de conflitos existentes entre os direitos coletivos garantidos aos povos indígenas pela $\mathrm{CF} / 88$ e os direitos daqueles que possuem os títulos de propriedade privada devidamente registrados em cartório e assegurados pelo CC/02, ensejando diversos processos judiciais relativos aos conflitos de interesse existentes ao redor de um mesmo bem.

O objetivo da pesquisa ora apresentada foi demonstrar que os conflitos envolvendo direitos coletivos indígenas e títulos de propriedade privada são questões atuais e corriqueiras no judiciário brasileiro, que culminam em diversos enfrentamentos entre povos indígenas e particulares, muitas vezes gerando danos imateriais, haja vista tratarmos aqui de povos com ligação profunda e espiritual com sua terra. Dessa forma, fica perceptível que os povos indígenas precisam de amparo estatal para conseguir manter sua identidade cultural e seu direito à terra, resguardados pela $\mathrm{CF} / 88$, sendo de responsabilidade do Estado utilizar meios, como por exemplo a demarcação das terras, para efetivar tais garantias e dar conhecimento à população nacional da destinação de tal espaço, no intuito de que não exista a alienação, consoante o direito privado brasileiro, das terras indígenas.

Assim, se mostra necessária a manutenção de políticas indigenistas públicas que visem assegurar aos povos indígenas a possibilidade de se manter fiel a seus modos e crenças, caso assim o deseje, não aspirando a sua assimilação à comunhão nacional. Discutir sobre o direito daqueles que se encontram em situação de minoria vulnerável é de suma importância quando verificamos conflitos práticos que precisam de uma análise mais profunda dentro da legislação e do sistema jurídico brasileiro, uma vez que estamos frente a normas garantidoras de direito, mas nos deparamos com constantes violações que influenciam no meio social e cultural dos povos nativos brasileiros.

\section{REFERENCIAS}

ALBUQUERQUE, Nayanne Alana Nanes de. Os direitos indígenas na legislação brasileira e o papel do Supremo Tribunal Federal na sua garantia. Repositório Digital ASCES, Caruaru, 2017. Disponível em: < http://repositorio.asces.edu.br/handle/123456789/928>. Acesso em: 14 de jul. 2019.

ANJOS FILHO, Robério Nunes dos. Direito ao Desenvolvimento de Comunidades Indígenas no Brasil. Biblioteca Digital de Teses e Dissertações da USP. São Paulo, 2009. Disponível em: $<$ http://www.teses.usp.br/teses/disponiveis/2/2133/tde-05012012-075449/pt-br.php>. Acesso em: 16 de ju. 2019. 
ARAÚJO, Ana Valéria. Povos indígenas e a Lei dos "Brancos": direito à diferença. Brasília: Ministério da Educação, Secretaria de Educação Continuada, Alfabetização e diversidade; LACED/Museu Nacional, 2006.

AZEVEDO, Álvaro Villaça. Curso de direito civil. Direito das coisas. São Paulo: Atlas, 2014.

BRASIL. Constituição da República Federativa do Brasil, de 1988. Disponível em: < http://www.planalto.gov.br/ccivil_03/constituicao/constituicaocompilado.htm>. Acesso em: 10 jul. 2019.

BRASIL. Decreto $n^{0} 1.775$, de 8 de janeiro de 1996. Disponível em: $<$ http://www.planalto.gov.br/ccivil_03/decreto/d1775.htm\#: :text=DECRETO\%20No\%201.7 $75 \% 2 \mathrm{C} \% 20 \mathrm{DE}, \mathrm{da} \% 20 \mathrm{Constitui} \% \mathrm{C} 3 \% \mathrm{~A} 7 \% \mathrm{C} 3 \% \mathrm{~A} 3 \mathrm{o} \% 2 \mathrm{C} \% 20 \mathrm{e} \% 20 \mathrm{no} \% 20$ art. . Acesso em: 03 julho 2019.

BRASIL. Diretório dos índios, 1755. Disponível em:

$<$ https://www.nacaomestica.org/diretorio_dos_indios.htm>.Acesso em: 18 jul. 2019.

BRASIL. Lei $\mathrm{n}^{\mathrm{o}}$ 10.406, de 10 de janeiro de 2002. Código Civil. Disponível em: $<$ http://www.planalto.gov.br/ccivil_03/leis/2002/110406compilada.htm>. Acesso em: 07 jul. 2019.

BRASIL. Lei no 6.001, de 19 de dezembro de 1973. Estatuto do índio. Disponível em: $<$ http://www.planalto.gov.br/ccivil_03/leis/16001.htm>. Acesso em: 18 jul. 2019.

BRASIL. Lei ${ }^{\circ}$ 601, de 18 de setembro de 1850. Disponível em:

$<$ http://www.planalto.gov.br/ccivil_03/leis/L0601-1850.htm>. Acesso em: 18 jul. 2019.

BRASIL. Lei no 13.844, de 18 de junho de 2019. Conversão da Medida Provisória $n^{0}$ 870, de 2019. Disponível em: <http://www.planalto.gov.br/ccivil_03/_ato2019-

2022/2019/lei/L13844.htm>. Acesso em: 10 nov. 2020.

BRASIL, Ministério Público Federal, Nota Técnica $n^{o} 1 / 2019-6^{a} C C R, 2019$. Disponível em: < http://www.mpf.mp.br/pgr/documentos/nota-tecnica-1.2019>. Acesso em 22 de abr. 2019.

BRASIL. Medida Provisória $n^{\circ} 870$, de $1^{\circ}$ de janeiro de 2019. Disponível em:

$<$ http://www.planalto.gov.br/ccivil_03/_ato2019-2022/2019/Mpv/mpv870.htm>. Acesso em 01 de mai. 2019.

BRASIL. Regulamento acerca das missões de catequese e civilização dos índios, 1845. Disponível em: $<$ http://legis.senado.leg.br/legislacao/DetalhaSigen.action?id=387574>. Acesso em 02 de mai. 2019.

BRASIL, Superior Tribunal de Federal. Ação Cível Originária 362. Indenização - Estado Terras indígenas. Comprovada a histórica presença indígena na área, descabe qualquer indenização em favor do Estado. Relator: Min. Marco Aurélio, Brasília, 16 de agosto de 2017. Lex: Jurisprudência do STF, Mato Grosso, n. p. 4119-4217, out. 2017. 
BRASIL, Superior Tribunal de Federal. Ação Cível Originária 366. Indenização - Estado Terras indígenas. Comprovada a histórica presença indígena na área, descabe qualquer indenização em favor do Estado. Relator: Min. Marco Aurélio, Brasília, 16 de agosto de 2017. Lex: Jurisprudência do STF, Mato Grosso, n. p. 2937-3049, out. 2017.

BRASIL, Supremo Tribunal Federal, Suspensão de Liminar. Agravo regimental na suspensão de liminar. Ação de reintegração de posse. Imóvel rural. Ocupação indígena tradicional. Ordem de retirada da comunidade indígena Tapeba. Estudo antropológico. Funai.

Procedimento demarcatório pendente. Relatório circunstanciado de revisão de limites. Risco de lesão à ordem e à segurança públicas. Agravo ao qual se nega provimento. Relator(a): Min. Cármen Lúcia (presidente), Ceará, 25 de setembro de 2018. Lex: Jurisprudência do STF, Ceará, set. 2018.

BRASIL, Tribunal Regional Federal da $3^{\text {a }}$ Região, Apelação Cível 000032892.2010.4.03.6002. Processo Civil. Demarcação. Terras indígenas. Município. Relator: Desembargador Federal Mauricio Kato, São Paulo, 05 de março de 2018. Lex: Jurisprudência do TRF-3, Mato Grosso do Sul, mar. 2018.

BRASIL, Tribunal Regional Federal da 4a Região, Apelação Cível 500351713.2014.4.04.7202/SC. Administrativo. Demarcação. Terras indígenas. Art. 231, da CF/88. Portaria de demarcação n ${ }^{\circ}$ 793/07 do Ministério da Justiça. Art. 1.201 do Código Civil. Benfeitorias. Indenização. Boa-fé não comprovada. Relator: Ricardo Teixeira do Valle Pereira, Porto Alegre, 26 de abril de 2016. Lex: Jurisprudência do TRF-4, Santa Catarina, abr. 2016.

CAVALCANTI, Thais Novaes. Direito ao desenvolvimento dos povos indígenas e bom governo: uma contribuição de Guaman Poma de Ayala e Francisco de Vitória. Revista de Direito Constitucional e Internacional, RDCI, vol. 96, n. 3, julho/agosto, 2016.

CUNHA, Manuela Carneiro. História dos índios no Brasil. São Paulo: Companhia das Letras, 2009.

FERNANDES, Marco Aurélio Soares. Limites do usufruto das terras da união por povos indígenas. Trabalho de Conclusão de Curso (Bacharelado em Direito) - Universidade Federal de Rondônia, Cacoal, 2016. Disponível em: $<$ http://www.ri.unir.br/jspui/handle/123456789/1057> Acesso em: 19 de abr. 2019.

FUNAI, Fundação Nacional do Índio. Terras indígenas: o que é?, 2019. Disponível em: $<\mathrm{http}$ //www.funai.gov.br/index.php/nossas-acoes/demarcacao-de-terras-indigenas? start=1\#>. Acesso em 06 de mar. 2019.

FUNAI, Fundação Nacional do Índio. Terras Indígenas. [s.d.]. Disponível em: $<$ http://www.funai.gov.br/index.php/indios-no-brasil/terras-indigenas $>$ Acesso em: 01 de abr. 2019.

GAGLIANO, Pablo Stolze. Código Civil Comentado. - Arts. 1.369 a 1.418, v. XIII. São Paulo: Atlas, 2004. 
GAGLIANO, Pablo Stolze. Manual de Direito Civil; volume único. / Pablo Stolze Gagliano e Rodolfo Pamplona Filho. - 2. ed. São Paulo: Saraiva Educação, 2018.

GONÇALVES, Carlos Roberto. Direito civil brasileiro; volume 5 - 14. ed. - São Paulo: Saraiva Educação, 2019.

IBGE, Instituto Brasileiro de Geografia e Estatística. Território brasileiro e povoamento. 2002. Disponível em: $<$ https://brasil500anos.ibge.gov.br/territorio-brasileiro-epovoamento/historia-indigena/terras-indigenas.html>. Acesso em 16 de abr. 2019.

ISA, Povos Indígenas no Brasil e o Instituto Socioambiental. Direitos constitucionais dos indios, 2018. Disponível em: $<$

https://pib.socioambiental.org/pt/Constitui\%C3\%A7\%C3\%A3o> Acesso em: 18 mai. 2019.

JOAQUIM, Ana Paula. Direito Constitucional Indígena - Uma análise à Luz do Caso Raposa/Serra do Sol. Biblioteca Digital de Teses e Dissertações da USP. São Paulo, 2013. Disponível em: $<$ http://www.teses.usp.br/teses/disponiveis/2/2134/tde-09122013-145825/ptbr.php>. Acesso em 03 de mar. 2019.

LÔBO, Paulo. Direito civil. Coisas. São Paulo: Saraiva, 2015.

LOPES, Ana Maria D'Ávila. UCHOA, Cibele Alexandre. A garantia do "ne bis in idem" e o reconhecimento dos direitos culturais dos indígenas $=$ The guarantee of "ne bis in idem" and the recognition of the cultural rights of indigenous people. Escola de Magistratura do Rio Grande do Norte (ESMARN). Revista Direito e Liberdade, Natal, v. 20, n. 2, p. 11-30, maio/ago. 2018.

PENA, Rodolfo F. Alves. Demarcação de terras indígenas no Brasil. Brasil Escola, 2019. Disponível em: $<$ https://brasilescola.uol.com.br/brasil/demarcacao-terras-indigenas-nobrasil.htm>. Acesso em 20 de jul. de 2019.

SANTAELLA, Lúcia. Culturas e artes do pós-humano: Da cultura das mídias à cibercultura. O que é cultural 1. 4 ed. São Paulo: Paulus, 2010.

SILVA, Elizângela Cardoso de Araújo. Povos indígenas e o direito à terra na realidade brasileira. Serv. Soc. Soc., São Paulo, n. 133, p. 480-500, 2018. Disponível em: < http://www.scielo.br/scielo.php?script=sci_arttext\&pid=S010166282018000300480\&lng=pt\&nrm=isso $>$ Acesso em 19 jul. 2019

SOUSA, Naira Regina do Nascimento. O dano sócio-ambiental em terras indígenas: a diversidade cultural e a concretização do direito ao meio ambiente sadio previsto da Constituição Federal de 1988. Repositório Institucional da UCS. Universidade de Caxias do Sul. Caxias do Sul, 2012. Disponível em:

$<$ https://repositorio.ucs.br/xmlui/bitstream/handle/11338/256/Dissertacao\%20Naira\%20Regin $\mathrm{a} \% 20 \mathrm{do} \% 20$ Nascimento $\% 20$ Sousa.pdf? sequence=1\&isAllowed=y $>$ Acesso em 18 jun. 2019.

SOUZA FILHO, Carlos Frederico Marés de. Multiculturalismo e direitos coletivos. In: Reconhecer para libertar. SANTOS, Boaventura de Souza (org.). 2. ed. Rio de Janeiro: Civilização Brasileira, 2010. 
SOUZA FILHO, Carlos Frederico. Os povos tribais da Convenção 169 da OIT. In: Revista de Direito UFG, v. 42, n. 3, p. 155-179, set/dez, 2018.

\section{DADOS DA PUBLICAÇÃO}

Categoria: artigo submetido ao double-blind review.

Recebido em: 31/07/2019.

Aceito em: 03/12/2020. 
(1)

N)

쇼요 